\title{
Cobalt (II)-Imidazolate Nanoparticles: Aqueous Synthesis and Physicochemical Characterization ${ }^{\dagger}$
}

\author{
Altair Victoria Marcos Gómez ${ }^{1, *}$, Brenda Velasco Rodríguez ${ }^{1}$, Lilia Guadalupe Arellano Galindo ${ }^{1}$, \\ Javier Fernández Vega ${ }^{1}$, Adriana Cambón Freire ${ }^{1}$, Abeer Al-Modlej ${ }^{2}$, Silvia Barbosa Fernández ${ }^{1}$ \\ and Pablo Taboada Antelo ${ }^{1}$
}

Citation: Gómez, A.V.M.; Rodríguez, B.V.; Galindo, L.G.A.; Vega, J.F.;

Freire, A.C.; Al-Modlej, A.; Fernández, S.B.; Antelo, P.T. Cobalt(II)-Imidazolate

Nanoparticles: Aqueous Synthesis and Physicochemical

Characterization. Mater. Proc. 2021, 4, 77. https://doi.org/10.3390/ IOCN2020-07992

Academic Editors: Ana María Díez-Pascual, Antonio Di Bartolomeo and Guanying Chen

\section{Published: 12 November 2020}

Publisher's Note: MDPI stays neutral with regard to jurisdictional claims in published maps and institutional affiliations.

Copyright: (C) 2020 by the authors. Licensee MDPI, Basel, Switzerland. This article is an open access article distributed under the terms and conditions of the Creative Commons Attribution (CC BY) license (http://creativecommons.org/licenses /by/4.0/).
1 Grupo de Física de Coloides y Polímeros, Facultad de Física, Universidade de Santiago de Compostela, 15705 Santiago de Compostela, Spain; brenda.velasco@rai.usc.es (B.V.R.); liliagarellanog@gmail.com (L.G.A.G.); javier.fernandez.vega@rai.usc.es (J.F.V.); adriana.cambon.freire@usc.es (A.C.F.); silvia.barbosa@usc.es (S.B.F.); pablo.taboada@usc.es (P.T.A.)

2 College of Science, King Saud University, Riyadh 11451, Saudi Arabia; amodlej@KSU.EDU.SA

* Correspondence: altairvictoria.marcos@rai.usc.es

† Presented at the 2nd International Online-Conference on Nanomaterials, 15-30 November 2020; Available online: https://iocn2020.sciforum.net/.

\begin{abstract}
During the last few years, Metal Organic Frameworks (MOFs) are being considered as ideal candidates to find more efficient systems for the production and storage of energy [1]. MOFs are characterized by their large specific surface due to ultra-high porosity, tunable pore size distribution and structural tailorability. These characteristics will determine the properties obtained, and derived from them, their potential applications such as clean energy storage [2], $\mathrm{CO}_{2}$ capture and other separation processes [3,4], biomedical imaging [5], optical luminescence and catalysis [6]. Recently, zeolitic structures based on imidazolates groups as organic ligand (ZIFs) have appeared as an important subfamily of MOFs which present a high surface area, adjustable pore size, thermal stability above $500{ }^{\circ} \mathrm{C}$ and high chemical stability in aqueous and organic media. The synthetic route developed for the fabrication of metallic crystalline networks composed of $\mathrm{Co}^{2+}$ and 2-methylimidazole is simple, carried out in aqueous medium and at room temperature. The synthetic process used in this work for obtaining MOFs is based on a surfactant method [7] in which different proportions of the constituents were used. The physicochemical characterization and the colloidal stability were carried out by dynamic light scattering (DLS), scanning transmission electron microscopy (STEM) and thermogravimetric analysis (TGA). Furthermore, we investigate the influence of the surfactant Cetyl Trimethyl Ammonium Bromide (CTAB) as well as the use of different solvents on the colloidal stability and the morphology, structure and chemistry of the synthesized systems.
\end{abstract}

Keywords: Metal Organic Frameworks; Zeolitic Imidazolate Frameworks; physicochemical characterization

Supplementary Materials: The poster presentation is available online at https://www.mdpi.com/ article/10.3390/IOCN2020-07992/s1. 


\section{References}

1. Wang, L.; Han, Y.; Feng, X.; Zhou, J.; Qi, P.; Wang, B. Metal-organic frameworks for energy storage: Batteries and supercapacitors. Coord. Chem. Rev. 2016, 307, 361-381, doi:10.1016/j.ccr.2015.09.002.

2. Ma, S.; Zhou, H.-C. Gas storage in porous metal-organic frameworks for clean energy applications. Chem. Commun. 2009, 46, 44-53, doi:10.1039/b916295j.

3. Sculley, J.P.; Li, J.-R.; Park, J.; Lu, W.; Zhou, H.-C.J. Metal-organic frameworks and porous polymer networks for carbon capture. Sustain. Technol. Syst. Policies 2012, 16, doi:10.5339/stsp.2012.ccs.16.

4. Pettinari, C.; Tombesi, A. Metal-organic frameworks for carbon dioxide capture. MRS Energy Sustain. 2020, 7, doi:10.1557/mre.2020.30.

5. Chedid, G.; Yassin, A. . Recent Trends in Covalent and Metal Organic Frameworks for Biomedical Applica-tions. Nanomaterials 2018, 8, 916 .

6. Allendorf, M.D.; Stavila, V.; Talin, A.A.; Ullman, A.M.; Wang, T.C. Metal-Organic Frameworks with Open Metal Sites for Sensing, Catalysis, and Energy Storage. In ECS Meeting Abstracts; IOP Publishing: Bristol, UK, 2018

7. Navarro Poupard, M.; Polo, E.; Taboada, P.; Arenas-Vivo, A.; Horcajada, P.; Pelaz, B.; del Pino, P. Aqueous Synt-hesis of Copper(II)-Imidazolate Nanoparticles. Inorg. Chem. 2018, 57, 12056-12065. 